\title{
Designing and Testing Controls to Mitigate Tower Dynamic Loads in the Controls Advanced Research Turbine
}

\section{Preprint}

A.D. Wright and L.J. Fingersh

National Renewable Energy Laboratory

\section{K.A. Stol}

Mechanical Engineering Department

University of Auckland

Auckland, New Zealand

To be presented at the $45^{\text {th }}$ AIAA Aerospace Sciences Meeting and Exhibit, Wind Energy Symposium

Reno, Nevada

January 8-11, 2007

Conference Paper NREL/CP-500-40932 January 2007 


\section{NOTICE}

The submitted manuscript has been offered by an employee of the Midwest Research Institute (MRI), a contractor of the US Government under Contract No. DE-AC36-99G010337. Accordingly, the US Government and MRI retain a nonexclusive royalty-free license to publish or reproduce the published form of this contribution, or allow others to do so, for US Government purposes.

This report was prepared as an account of work sponsored by an agency of the United States government. Neither the United States government nor any agency thereof, nor any of their employees, makes any warranty, express or implied, or assumes any legal liability or responsibility for the accuracy, completeness, or usefulness of any information, apparatus, product, or process disclosed, or represents that its use would not infringe privately owned rights. Reference herein to any specific commercial product, process, or service by trade name, trademark, manufacturer, or otherwise does not necessarily constitute or imply its endorsement, recommendation, or favoring by the United States government or any agency thereof. The views and opinions of authors expressed herein do not necessarily state or reflect those of the United States government or any agency thereof.

Available electronically at http://www.osti.gov/bridge

Available for a processing fee to U.S. Department of Energy and its contractors, in paper, from:

U.S. Department of Energy

Office of Scientific and Technical Information

P.O. Box 62

Oak Ridge, TN 37831-0062

phone: 865.576 .8401

fax: 865.576 .5728

email: mailto:reports@adonis.osti.gov

Available for sale to the public, in paper, from:

U.S. Department of Commerce

National Technical Information Service

5285 Port Royal Road

Springfield, VA 22161

phone: 800.553 .6847

fax: 703.605.6900

email: orders@ntis.fedworld.gov

online ordering: http://www.ntis.gov/ordering.htm 


\title{
Designing and Testing Controls to Mitigate Tower Dynamic Loads in the Controls Advanced Research Turbine
}

\author{
Alan D. Wright ${ }^{*}{ }^{\dagger}$, Lee J. Fingersh ${ }^{*}$ \\ National Renewable Energy Laboratory \\ Golden, Colorado 80401 \\ Karl A. Stol ${ }^{\S}$ \\ Department of Mechanical Engineering \\ The University of Auckland \\ Private bag 92019 \\ Auckland, New Zealand
}

\begin{abstract}
One goal of the U.S. Wind Energy Program is to design fatigue-resistant wind turbines. Control systems must be developed to mitigate structural loads to reduce costs and make wind energy a significant part of the U.S. electricity demand. Control systems that minimize fatigue loads without sacrificing turbine power while maintaining stable closed-loop behavior in the presence of turbulent wind inflow are critical for new large turbine designs.

Classical design methods such as Proportional-Integral-Derivative control are used to design typical commercial wind turbine controllers. These methods are based on a single input and single output. As wind turbines become larger and more flexible, the potential for the control system to destabilize weakly damped flexible turbine modes increases. With modern advanced control design methods, multiple control objectives can be met with a single control loop, which leads to a stable closed-loop system.

At the National Renewable Energy Laboratory we are designing, implementing, and testing advanced controls to maximize energy extraction and reduce structural dynamic loads. These control designs are based on a linear model of the turbine that is generated by specialized modeling software. In this paper we show the design, implementation and testing of a control algorithm to actively damp the tower's fundamental side-side and fore-aft mode. This control algorithm combines generator torque and blade pitch control in a single control loop.
\end{abstract}

\section{Introduction}

Typical variable-speed wind turbines have different regions of operation. In below rated wind speeds (Region 2) blade pitch is held constant, and generator torque control is used to vary the speed of the turbine to maximize energy capture. In above-rated wind speeds (Region 3), generator torque is held constant, and blade-pitch control is used to limit aerodynamic power to maintain constant turbine speed. Another important goal of turbine control is to reduce structural dynamic loads in both operating regions.

\footnotetext{
* Employees of the Midwest Research Institute under Contract No. DE-AC36-99GO10337 with the U.S. Dept. of Energy have authored this work. The United States Government retains, and the publisher, by accepting the article for publication, acknowledges that the United States Government retains a non-exclusive, paid-up, irrevocable, worldwide license to publish or reproduce the published form of this work, or allow others to do so, for the United States Government purposes.

† Senior Engineer, National Wind Technology Center, 1617 Cole Blvd., Mailstop 3811, AIAA member

* Senior Engineer, National Wind Technology Center, 1617 Cole Blvd., Mailstop 3811, AIAA nonmember

$\S$ Lecturer, AIAA member
} 
One method of reducing dynamic loads is to design controls to provide active damping of turbine components. Designing controls that reduce blade, tower, and drive-train dynamic loads - and thereby extend fatigue life-is particularly important. In Region 3, classical control design methods have been used to design controllers to add damping to the tower's first fore-aft (f-a) mode with blade pitch. ${ }^{1,2}$ These methods use a notch filter to provide an additional pitch input in such a way as to increase the damping in that mode. Similar methods could also be used to actively damp the tower's first side-side (s-s) mode with generator torque control, although this method is not discussed in the literature. A disadvantage of classical control methods is that multiple control loops must be used to simultaneously dampen several flexible turbine modes. If these controls are not designed with great care, these control loops interfere with each other and cause the turbine to become unstable. The potential to destabilize the turbine grows as turbines become larger and more flexible, and the degree of coupling between flexible modes increases. Using all the available turbine actuators in a single control loop to maximize load-alleviating potential would be advantageous. Advanced multi-input multi-output (MIMO) multivariable control design methods, such as those based on state-space models, can be used to meet these multiple control objectives and use all the available actuators and control inputs in a single control loop.

In previous papers, we have shown the design of state-space controllers to regulate turbine speed in Region 3 and enhance damping of flexible turbine modes. ${ }^{3-6}$ Those papers showed the advantages of using full-state feedback to place turbine plant poles to enhance transient response and increase stability. When limited turbine measurements are available, state estimation must be used. Without state estimation, every state contained in the linearized controller design model must be measured, which is not practical for most commercial turbines. Successful use of state estimation is based on a few turbine measurements such as generator speed and tower-top acceleration. In other work, state-space methods were used to design controls that maximize energy extraction and reduce fatigue loads in Region 2 using pitch control. ${ }^{7}$ In that study, individual pitch control was shown through simulation to reduce blade fatigue damage equivalent loads (DELs) by $11 \%$.

Actual field implementations of these turbine controls have verified the capability of these state estimating controls to mitigate loads by using blade pitch as the control actuator. ${ }^{8-10}$ In addition, actual tests have shown that generator torque is an effective control actuator that actively damps the first drive-train torsion mode in Regions 2 and 3. ${ }^{11}$ Other field implementations of controls on the Controls Advanced Research Turbine (CART) have used adaptive control techniques to improve Region 2 energy capture compared to the simpler Region 2 torque controls. ${ }^{12}$

The tower bending modes also benefit from active damping. We are interested in the potential benefits of using the generator torque and blade pitch actuators together to actively damp the tower s-s and f-a bending modes. This control should be performed in a single control loop because of the large amount of coupling between these two modes. These controllers will require an additional measurement, such as tower-top acceleration or tower strain, to ensure that states representing the tower motion are estimated properly.

In this paper we show the design, implementation and tests of a MIMO controller to add damping to the tower's first f-a and first s-s bending modes, as well as the first drive-train torsion mode. The controller uses perturbations in generator torque and blade pitch to apply this active damping. Typical control inputs are generator speed and towertop f-a and s-s acceleration (although we started with tower strain data). We restrict attention in this paper to design of control for Region 2. The controller is based on full state feedback but uses state estimation based on these measurements.

We describe steps taken in the control design process. We show implementation and tests of this controller on the CART at the National Wind Technology Center. We describe lessons learned from implementing these controls in the CART. We show load alleviating potential of this controller by comparing results to a baseline controller with no tower damping capability. We finally state conclusions and outline future work.

\section{CART Configuration}

The CART (Fig. 1) is a two-bladed, teetered, upwind, active-yaw wind turbine. This machine is used as a test bed to study aspects of wind turbine control technology for medium- to large-scale machines. ${ }^{13}$ 
The CART is variable speed, and each blade is capable of being independently pitched with its own electromechanical servo. The pitch system can pitch the blades up to 18 degrees per second (deg/s) with pitch accelerations up to 150 degrees per second per second. The squirrel cage induction generator with full power electronics can control torque from minus rating (motoring) to plus rating (generating) at any speed. The torque control loop has a very high rated bandwidth of 500 radians per second $(\mathrm{rad} / \mathrm{s})$.

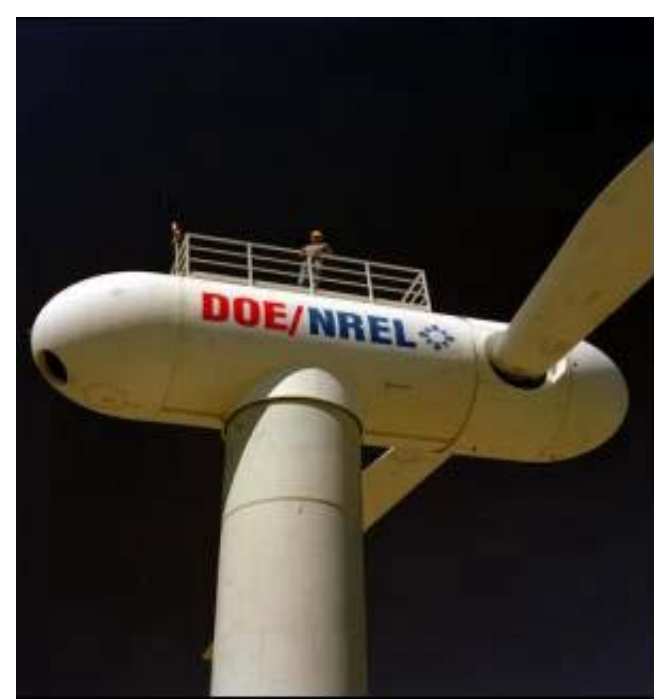

Figure 1. The controls advanced research turbine (CART).

Rated electrical power (600 kilowatts at a low-speed shaft [LSS] speed of 41.7 revolutions per minute [rpm]) is maintained in Region 3 in a conventional variable-speed approach. Power electronics are used to command constant torque from the generator and full-span blade pitch controls the rotor speed.

The machine is equipped with a full complement of instruments that gather meteorological data at four heights. Blade-root flap and edge-strain gages, tower-bending gages, and low-speed shaft (LSS) and high-speed shaft (HSS) torque transducers gather load data. Accelerometers in the nacelle measure the tower's f-a and s-s motion. Absolute position encoders gather data on pitch, yaw, teeter, LSS, and HSS positions. These data are sampled at $100 \mathrm{~Hz}$. The custombuilt control system collects these data and controls the turbine at a control loop cycle rate of $100 \mathrm{~Hz}$. This system is personal computer based and very flexible.

For the baseline turbine controls, the generator torque is varied in Region 2 according to the expression

$$
T=k w^{2},
$$

where $T$ is generator torque, $k$ is a constant, and $w$ is rotor speed. ${ }^{13}$ In this region, blade pitch is constant, and the constant $k$ is chosen to maintain turbine operation at the tip-speed ratio (tsr) corresponding to maximum power coefficient $\mathrm{Cp}$. This provides a simple way to design a generator torque controller for Region 2 .

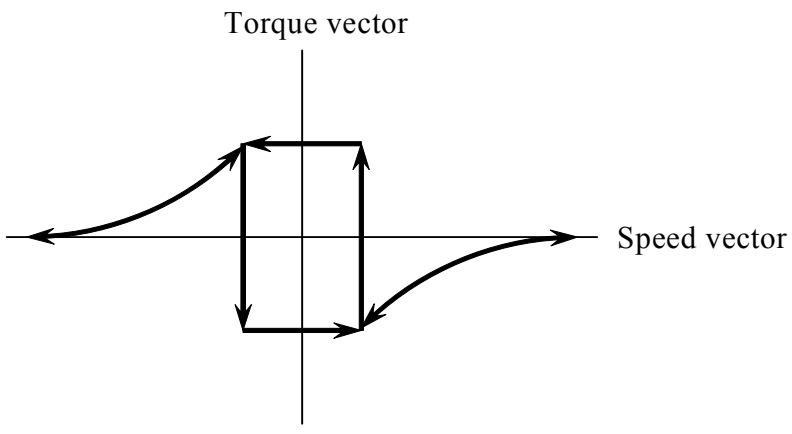

Figure 2. Tower resonance avoidance strategy. Demanded torque with speed hysteresis is used to avoid operation at or near the resonance point.
Within the normal operating speeds of the CART, loads transmitted from the 2-bladed rotor (at two times the rotor rotation rate $[2 \mathrm{P}]$ ) to the tower can drive the tower at its first natural frequency. To alleviate this problem, we developed a strategy for the baseline controller to avoid operating it at a rotor speed that can cause this resonance. ${ }^{13}$ The tower resonance avoidance strategy employs the simple torque controller found in Fig. 2. This curve is designed to multiply the standard control law (depicted as the horizontal line) to give a final torque demanded vector. As rotor speed increases, the controller is designed to prevent the rotor speed from reaching the resonance point until aerodynamic torque is sufficient to allow the rotor to run through the resonance rapidly. When speed is decreasing, the opposite strategy is employed. Speed is kept above the resonance point until aerodynamic torque has fallen sufficiently to allow the machine to apply shaft torque of sufficient magnitude to rapidly slow the machine through the resonance point.

One challenge of wind turbine control design is meeting multiple control objectives. While maximizing energy in Region 2 and maintaining constant turbine speed in Region 3, we must also reduce dynamic loads to obtain longer 
turbine lifetimes and reduce the cost of energy. If controls are not carefully designed to account for the flexible modes of the wind turbine, we can actually increase dynamic loads by destabilizing low-damped modes. We now describe the design of state-space controls for Region 2 that allow us to meet the primary objectives in this region and enhance the damping in the tower's first $\mathrm{f}$-a and s-s modes, as well as the first drive-train torsion mode.

\section{State-Space Control Design}

We restrict our attention in this paper to control design in Region 2. The main goal in Region 2 is to control generator torque so the power is maximized. A second objective for our control is to mitigate tower-bending loads. We will use generator torque and blade pitch to add damping to the tower's first s-s and f-a modes as well as the first drive-train torsion mode to reduce loads.

In this paper, we perform overall generator torque control to maximize power by directly applying the torque expression in Eq. (1), which describes the baseline generator torque controller for the CART. Normally, pitch is held constant in this region. We apply the state-space controls as perturbations of torque and pitch on top of these values to add damping to the tower's first f-a and s-s modes, as well as the first drive-train torsion mode. Only the tower and drive-train damping is performed with the state-space controller; the overall generator torque control to maintain optimum $\mathrm{Cp}$ is performed as in Eq. (1). These performance objectives drive the complexity of the state-space controller and the selection of turbine sensors for feedback.

A linear time-invariant state-space model of the CART is described by

$$
\begin{aligned}
& \underline{\dot{x}}=A \underline{x}+B \underline{u} \\
& \underline{y}=C \underline{x}+D \underline{u}
\end{aligned}
$$

where $\underline{u}$ is the vector of control inputs: perturbed generator torque and perturbed collective blade pitch rate. ${ }^{9} \underline{x}$ and $y$ are the state vector and measurement vector respectively, described below. The state matrices $(A, B, C$, and $D)$ are found by linearizing a FAST aero-elastic model of an operating point in Region $2 .{ }^{14}$ This operating point is defined by a rotor speed of $27.1 \mathrm{rpm}$ and hub-height wind speed of 8.0 meters per second $(\mathrm{m} / \mathrm{s})$. In this context, "perturbed" refers to small deviations from the turbine linearization point.

Twelve state variables in $\underline{x}$ are chosen to characterize the structural dynamics of interest. These state variables include

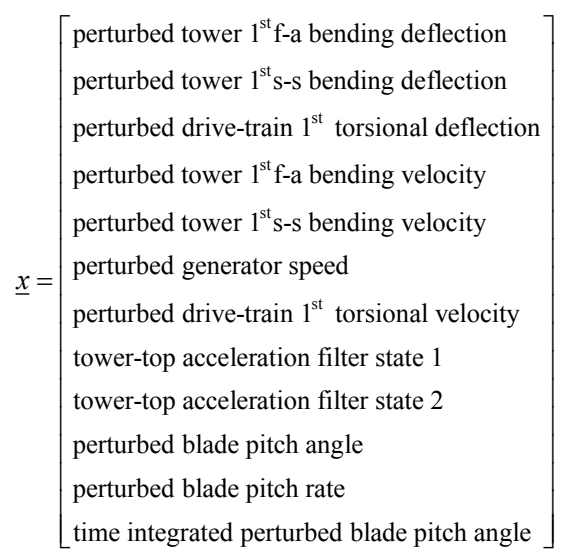

We will further describe the tower-top acceleration filter states in the next section. 
The control input $\underline{u}$ consists of:

$\underline{u}=\left[\begin{array}{l}\text { perturbed generator torque } \\ \text { perturbed blade pitch rate }\end{array}\right]$

Five measurements in $\underline{y}$ are selected to ensure observability for state estimation. The measurements correspond to the output of physical sensors on the CART, including

$\underline{y}=\left[\begin{array}{l}\text { perturbed generator speed } \\ \text { perturbed blade pitch angle } \\ \text { time-integrated perturbed blade pitch angle } \\ \text { perturbed tower-top fore-aft acceleration } \\ \text { perturbed tower-top side-side acceleration }\end{array}\right]$

Based on the state-space CART model, a state estimator is formed:

$$
\underline{\dot{\hat{x}}}=(A-K C) \underline{\hat{x}}+B \underline{u}+K \underline{y}
$$

where $\underline{\hat{x}}$ is the estimate of plant states. Full-state feedback is used to produce controller commands for generator torque and pitch rate.

$$
\underline{u}=G \underline{\hat{x}}
$$

The control gains $G$ and $K$ are calculated using the linear quadratic regulation (LQR) method in MATLAB. ${ }^{15}$ This approach for gain calculation allows us to trade off state regulation with actuator effort. To add tower damping in particular, the states that correspond to tower-top rates of deflection are weighted most heavily.

The block diagram in Fig. 3 illustrates how the state-space controller is implemented in simulation and with the actual CART machine. The conventional variable speed controller is still present to provide nominal generator torque commands for Region 2 control, based on Eq. (1). The state-space controller augments this generator torque signal to achieve the desired tower damping.

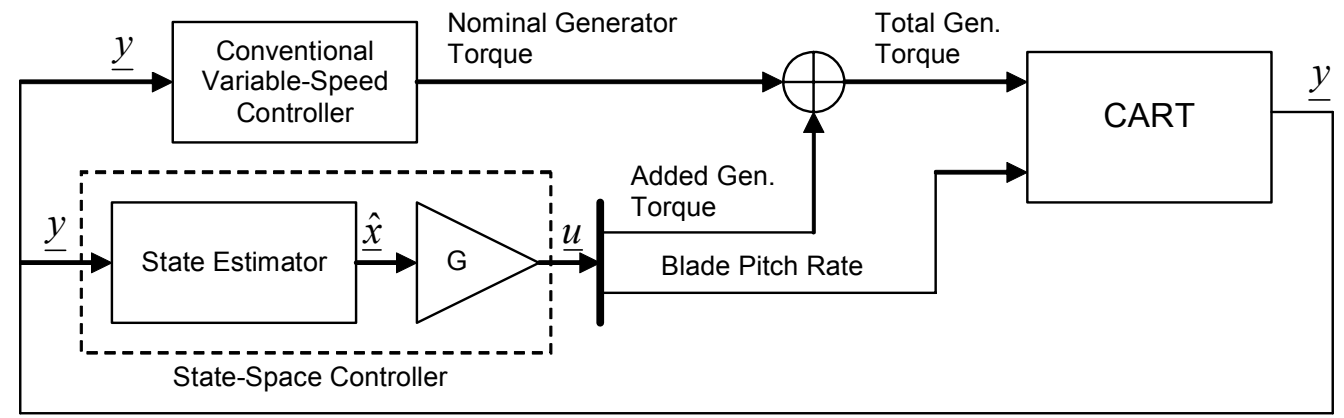

Figure 3. State-space controller implementation.

We designed, implemented, and tested simpler controllers to simplify implementation and work up in steps before we implemented and tested this "full-up" MIMO controller. We now describe these implementation steps. 


\section{Implementation Steps and Lessons Learned}

We performed several intermediate steps before we designed, implemented, and tested the full-up MIMO controller. One step was to design and implement separate generator torque and blade pitch controllers. We felt that designing and implementing simpler controllers would help uncover implementation issues before we progressed to the MIMO controller. We also wanted to assess the required generator torque and blade pitch perturbations necessary to actively damp the tower's s-s and f-a motions.

One problem we encountered was the use of accelerometer data as input to our controllers. Accelerometers are often plagued with noise problems, which introduce another degree of complexity to the control design and implementation process. Before employing tower-top acceleration as the control input, we decided to first use straingages close to the tower base as the inputs to the control algorithms. Figure 4 shows the tower and nacelle instrumentation that we used in the course of this study. The tower strain gages were mounted in the east/west and north/south directions and were fixed to the tower above the foundation.

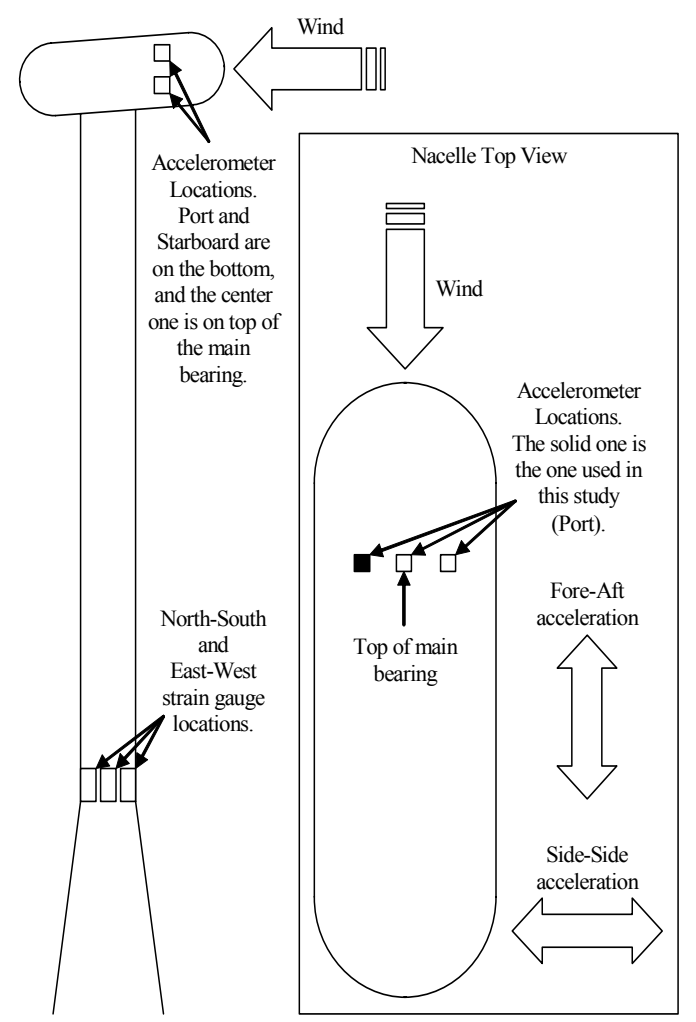

Figure 4. Location of tower strain gages and accelerometers used for control inputs.
The first controller we designed and implemented on the CART used only the generator as a transducer to add damping to the tower first s-s mode, reading tower strain gage data (using tower bending moment as the control input). Even though we did not use pitch as an actuator to add damping to the tower's first $\mathrm{f}$-a mode, we included this mode in the linear model for control design. Including the tower $1^{\text {st }}$ f-a mode was necessary so that the generator torque controller would have information regarding the first f-a mode to eliminate the possibility of destabilizing this mode.

The state-space model for this control consisted of states representing the tower first $\mathrm{s}-\mathrm{s}$, first $\mathrm{f}-\mathrm{a}$, first drive-train torsion mode, and generator speed. For this linear model, the state vector and control input were:

$\underline{x}=\left[\begin{array}{l}\mathrm{x}_{1}=\text { perturbed tower } 1^{\text {st }} \mathrm{f} \text {-a bending deflection } \\ \mathrm{x}_{2}=\text { perturbed tower } 1^{\text {st }} \mathrm{s}-\mathrm{s} \text { bending deflection } \\ \mathrm{x}_{3}=\text { perturbed drive-train } 1^{\text {st }} \text { torsional deflection } \\ \mathrm{x}_{4}=\text { perturbed tower } 1^{\text {st }} \mathrm{f} \text {-a bending velocity } \\ \mathrm{x}_{5}=\text { perturbed tower } 1^{\text {st }} \text { s-s bending velocity } \\ \mathrm{x}_{6}=\text { perturbed generator speed } \\ \mathrm{x}_{7}=\text { perturbed drive-train } 1^{\text {st }} \text { torsional velocity }\end{array}\right]$

$\underline{u}=\delta T_{\text {gen }}:$ perturbed generator torque. 
The inputs to the state estimator controller were:

$$
\underline{y}=\left[\begin{array}{l}
\text { perturbed generator speed } \\
\text { perturbed tower-base fore-aft bending moment } \\
\text { perturbed tower-base side-side bending moment }
\end{array}\right]
$$

The strain gages are attached to the tower (fixed frame), so a transformation involving nacelle yaw position was used to transform these measurements to the f-a and s-s directions (in the nacelle frame), before inputting to the controller.

We designed this controller from a linear turbine model generated by $\mathrm{FAST}^{14}$ at the turbine operating point:

Wind speed $=8 \mathrm{~m} / \mathrm{s}$

Rotor speed $=27.1 \mathrm{rpm}$

Pitch angle $=-1$ degree (normal Region 2 "run-pitch").

The goal of state-space control design is to use full state feedback to place the poles of the plant to obtain the desired stability and transient response. Without full state feedback, the eigenvalues of the matrix at this operating point have the values shown in Table 1 as the open-loop poles. We used LQR to design this controller. ${ }^{15}$ With full state feedback, and selection of appropriate LQR weights, the closed-loop poles are shown in Table 1. The largest weightings were placed on the states that corresponded to the tower's first s-s mode as well as the drive-train first torsion mode. This resulted in increased damping, as can be seen from the real parts of these poles (moved farther to the left in the complex plane). We placed only small weighting on the states that corresponded to the tower's first f-a mode as well as the generator speed state.

Table 1. Open-loop and Closed-loop Pole Locations

\begin{tabular}{|c|c|c|}
\hline & Open-loop poles & Closed-loop poles \\
\hline drive-train $1^{\text {st }}$ torsion & $-.003 \pm 22.47 \mathrm{i}(\mathrm{rad} / \mathrm{s})$ & $-1.09 \pm 22.47 \mathrm{i}(\mathrm{rad} / \mathrm{s})$ \\
\hline tower $1^{\text {st }}$ f-a mode & $-0.034 \pm 5.50 \mathrm{i}(\mathrm{rad} / \mathrm{s})$ & $-0.034 \pm 5.50 \mathrm{i}(\mathrm{rad} / \mathrm{s})$ \\
\hline tower $1^{\text {st }}$ s-s mode & $-0.001 \pm 5.54 \mathrm{i}(\mathrm{rad} / \mathrm{s})$ & $-0.197 \pm 5.54 \mathrm{i}(\mathrm{rad} / \mathrm{s})$ \\
\hline generator speed & -0.03 & -0.05 \\
\hline
\end{tabular}

We first simulated turbine behavior with this controller to assess its tower-damping capability and the required generator torque fluctuations for this damping. Figure 5 shows the open-loop and closed-loop tower's s-s bending moments from this simulation, as well as rotor speed. In this simulation, step winds were used as the input, so that the rotor speed would start below and pass through the 2-per-revolution (2P) excitation of the tower's first s-s mode, at about $26.5 \mathrm{rpm}$ (at this rotor speed [2.78 rad/s], $2 \mathrm{P}=5.56 \mathrm{rad} / \mathrm{s}$, which corresponds to the tower $1^{\text {st }} \mathrm{s}-\mathrm{s}$ mode). A dramatic reduction in the tower's s-s bending moments is seen with tower damping control (closed loop) compared to the case without tower damping control (open loop). Increasing the real part of the poles that correspond to the tower's first s-s mode from -0.001 (open-loop) to -0.197 (closed-loop) provides this load reduction. Figure 6 shows the simulated generator torque for open-loop and closed-loop cases. For the closed-loop case, torque perturbations are superimposed on top of the overall torque variation. These perturbations correspond to the commanded generator torque that actively damps the tower's first s-s mode. No perturbations are seen for the open-loop case. The largest generator torque perturbations (approximately $500 \mathrm{Nm}$ ) occur for rotor speeds of approximately $26.5 \mathrm{rpm}$, when the rotor provides $2 \mathrm{P}$ excitation of the tower. 


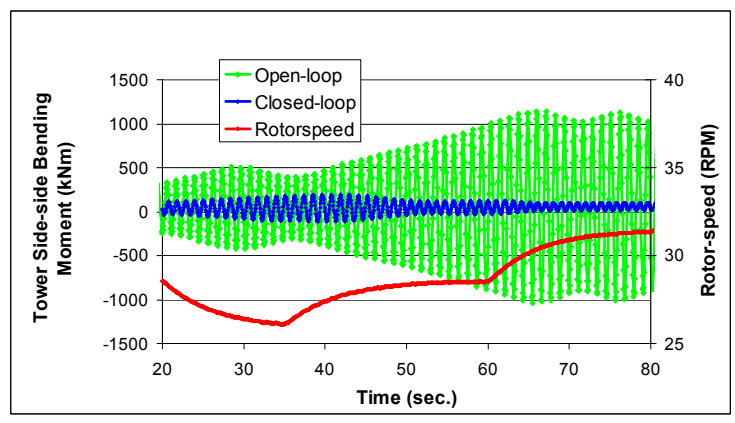

Figure 5. Simulation of tower side-side bending moments in open- and closed-loop showing load attenuation in closed-loop.

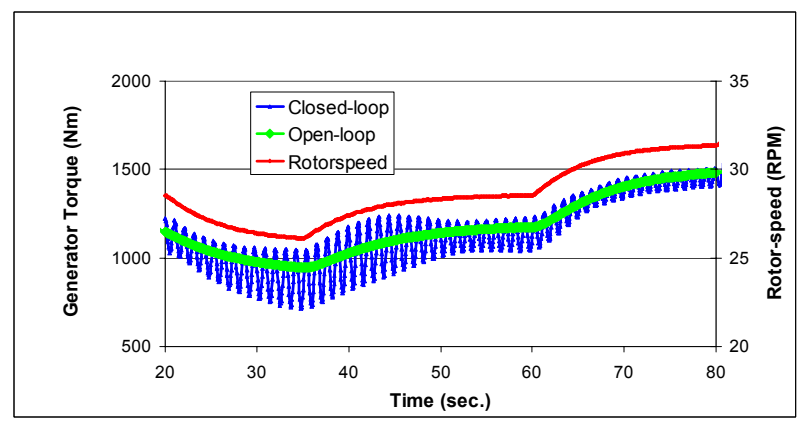

Figure 6. Simulation of generator torque in openand closed-loop for the case shown in Fig. 5.

We implemented and tested the tower damping controller on the CART. We tried to compare results from this controller to a baseline controller with no tower damping. A direct comparison of results is difficult because the controllers are tested at different times. We attempted to choose datasets that had similar statistics with excitation of the tower modes at $2 \mathrm{P}$ for both datasets. Figure 7 shows the tower's s-s bending moments from these two controllers. These are not identical datasets; the operating conditions and wind speeds are different for the baseline case compared to the state-space case. Still, the state-space case shows a significant reduction in cyclic loads compared to the baseline case. This is a direct result of using full-state feedback (as previously seen in simulation) to add damping to the tower's first s-s mode. Figure 8 shows commanded generator torque for the two cases, showing the degree of torque fluctuations at the tower's first s-s frequency for the state-space case. Overall we observed higher torque fluctuations in the actual test of this controller than in simulation, possibly because the turbine in the real case is impacted by turbulent wind fluctuations (which have spatial variations across the rotor disk). In simulation, only step winds were applied. In addition, the actual system could have a smaller amount of damping than the simulation model, which would result in greater torque variations.

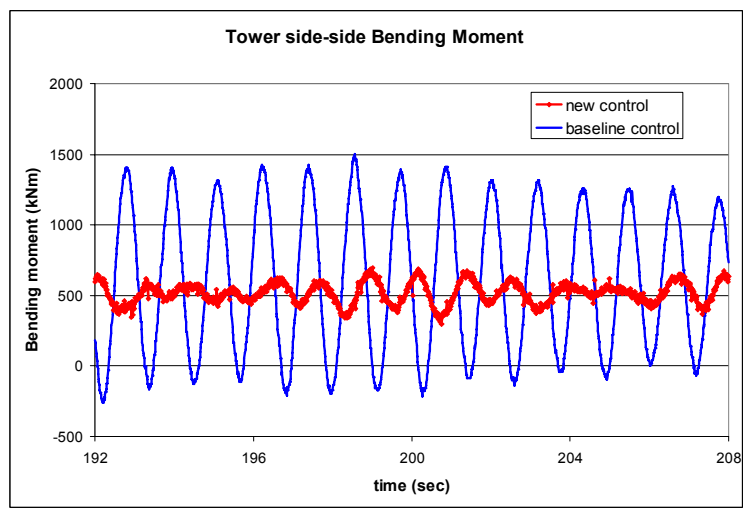

Figure 7. Measured tower side-side bending moment from the new control compared to the baseline control in the region of tower resonance.

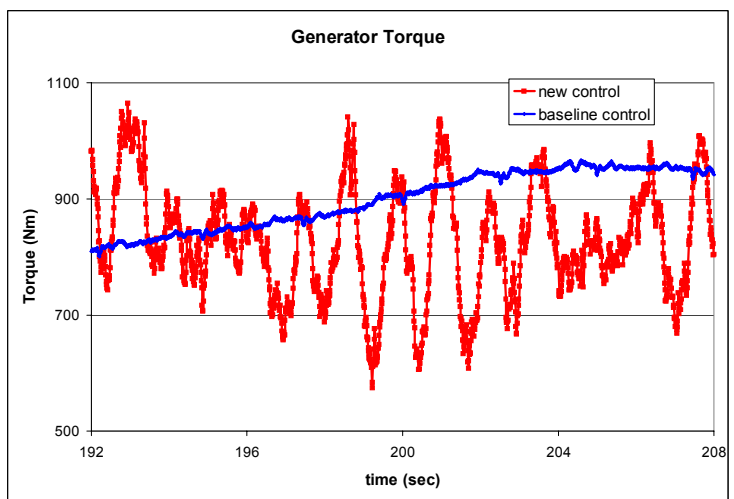

Figure 8. Measured generator torque from the new control compared to the baseline control in the region of tower resonance.

After successfully implementing and testing this controller, we decided to change the control input from tower bending moment to tower-top acceleration. This change eliminated the need for a coordinate transformation and is more representative of sensors used in the wind turbine industry. The linear model for control design had the same states as in Eq. (8), but the control input y is now 
$\underline{y}=\left[\begin{array}{l}\text { perturbed generator speed } \\ \text { perturbed tower-top fore-aft acceleration } \\ \text { perturbed tower-top side-side acceleration }\end{array}\right]$

The controller was designed at the same linearization point as the last controller. After we implemented and tested this controller on the CART, we discovered that the commanded generator torque reflected the high frequency vibrations contained in the tower-top accelerometer data. Figure 9 shows measured tower s-s acceleration data and commanded generator torque which reflect these high frequency vibrations.

To resolve this problem, we had to first filter the tower acceleration data before using it as an input to the controller. Even a filter that attenuates high-frequency vibrations can change the phase of a signal at low frequencies. We were concerned with this phase shift, because it would cause the commanded generator torque to be applied at the wrong phase and destabilize the tower's s-s motion. This phase effect must be accounted for in the controller so torque commands will be applied at the correct phase. One way to do this is to represent a model of the filter in the linear model used for control design. In this way, the controller has the information it needs about the filter to apply torque fluctuations at the correct phase angle to stabilize the tower's s-s motion.

We selected a second-order filter with the following transfer function:

$F(s)=\frac{0.03 s+30.0}{s^{2}+15.0 s+30.0}$

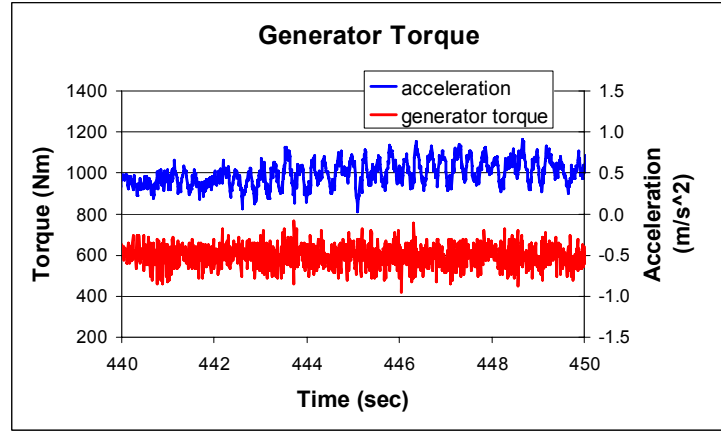

Figure 9. Measured tower side-side acceleration and generator torque BEFORE filtering acceleration.

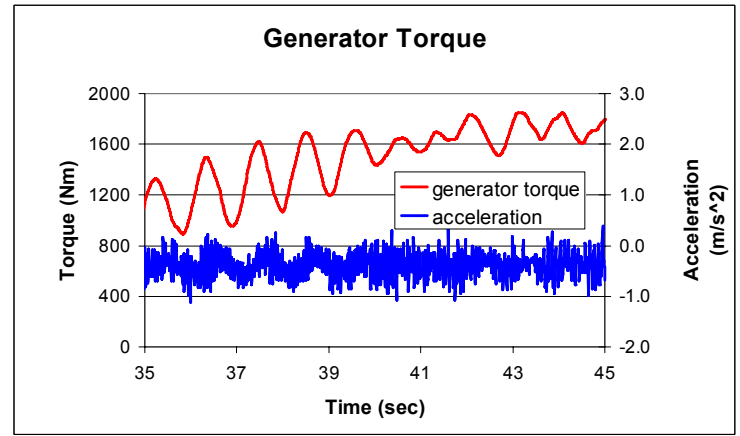

Figure 10. Measured tower side-side acceleration and generator torque AFTER filtering acceleration.

This filter provided the characteristics necessary to attenuate accelerometer response at high frequency. We added two extra states to the state vector to add the dynamics of this second-order filter to the control model. In addition, the state matrices in Eq. (2) were amended with the necessary values to describe the dynamics of this filter.

We then implemented and tested a revised controller designed from this linear model on the CART. Figure 10 shows measured generator torque and tower s-s acceleration with this new controller. Now the commanded generator torque is smooth and applies the correct phase to actively damp the tower's s-s motion, due to correct filtering of the accelerometer signal.

Further tests were performed with this controller in Region 2 operation. For rotor speeds up to 38 rpm the controller behaves as expected and adds damping to the tower's first s-s mode as designed. For rotor speeds of 38 to $39 \mathrm{rpm}$, the controller appears to excite unmodeled dynamics. Figure 11 shows measured generator torque and rotor speed for a case when this excitation occurs. The rotor speed begins at $39 \mathrm{rpm}$ and decreases to $37 \mathrm{rpm}$ toward the 
end of the record. As the rotor speed passes through $38.5 \mathrm{rpm}$, a significant increase in amplitude occurs at a frequency of approximately $1.3 \mathrm{Hertz}$ (Hz.). As the rotor speed decreases below $38.5 \mathrm{rpm}$, the amplitudes decrease. Figure 12 shows the measured tower's first f-a and s-s acceleration. Clearly these accelerometers are measuring excitation at $38.5 \mathrm{rpm}$ and the generator torque fluctuations reflect this excitation, because tower-top accelerometer data are being input to the controller.

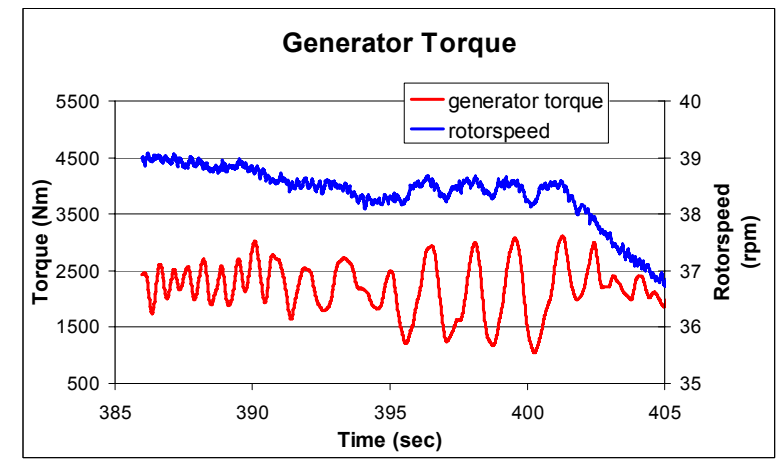

Figure 11. Measured generator torque for turbine operation at 37 to $39 \mathrm{rpm}$ with new controller.

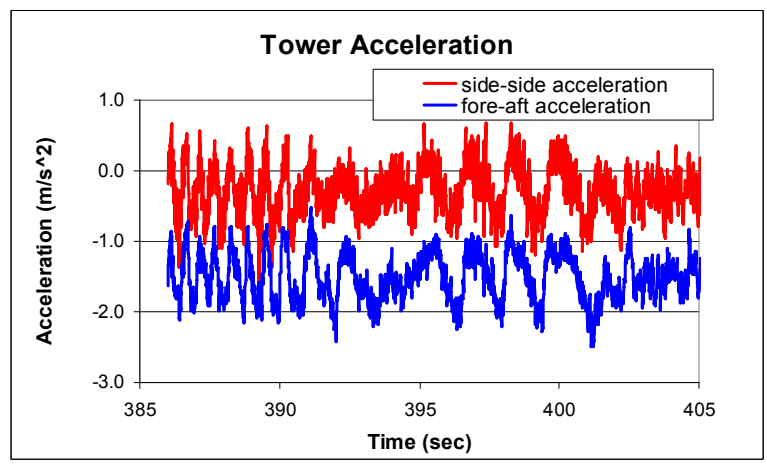

Figure 12. Measured tower side-side and fore-aft acceleration for the case shown in Fig. 10.

We needed to determine if this excitation was caused by the new state-space tower damping controller. We examined datasets from the baseline controller (which has no tower damping) and found similar excitation as that shown in Figure 12. This showed us that the state-space controller was not the cause of this excitation.

Next we wanted to review code simulations to see if they revealed excitation at this rotor speed. We reviewed the FAST simulations with this controller for rotor speeds of 38 to $39 \mathrm{rpm}$. These simulations failed to show any excitation like that seen in the measured data. Clearly this is a case of excitation of un-modeled dynamics. It is important to design controllers to account for such un-modeled dynamics.

A solution to correct control design would be to further filter the tower-top acceleration data to reduce the accelerometer response at the natural frequency that corresponds to this excitation before it is input to the controller.

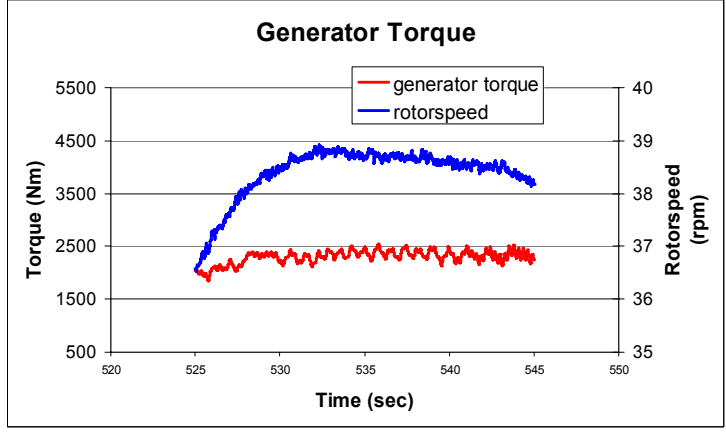

Figure 13. Measured generator torque for turbine operation at 37 to $39 \mathrm{rpm}$ with revised new controller.

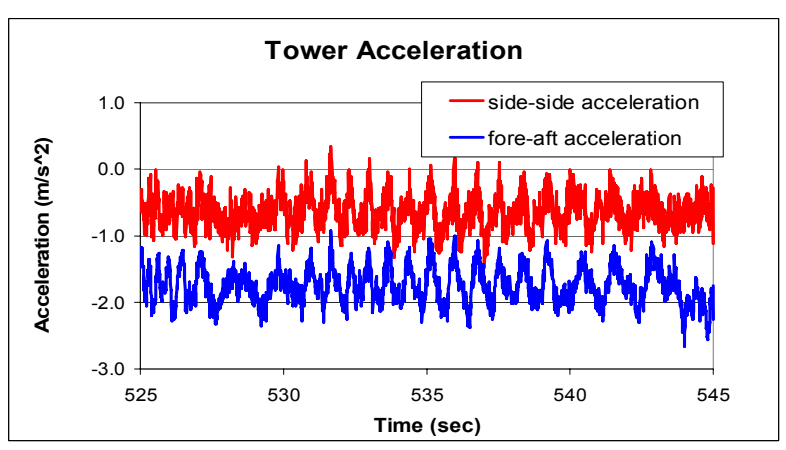

Figure 14. Measured tower side-side and fore-aft acceleration for the case shown in Fig. 13.

This would prevent the generator torque controller from responding at this frequency. It is not easy to design a filter that retains the proper information at the tower's first s-s and f-a natural frequencies (at about $5.5 \mathrm{rad} / \mathrm{s}$ ), yet attenuates response at the frequency corresponding to a $2 \mathrm{P}$ excitation at $38.5 \mathrm{rpm}(8.0 \mathrm{rad} / \mathrm{s})$. We will investigate the proper filter design to accomplish these objectives in future work. For this paper, we simply designed a second 
controller with reduced tower damping gains and scheduled it (based on rotor speed) to be active for rotor-speeds of 38 to $39 \mathrm{rpm}$.

We implemented and tested this revised controller. Figures 13 and 14 show measured generator torque and tower acceleration from this new controller at $38.5 \mathrm{rpm}$. Even though the excitation again shows up in the tower acceleration data, the generator torque perturbations are greatly reduced, compared to the previous controller. This reduction is due directly to the reduction of tower damping gains in this controller.

Another issue we resolved in implementation of these controls was the non-zero mean value of the tower-top s-s and $\mathrm{f}$-a acceleration data, seen in Figures 12 and 14. We found it necessary to subtract these mean values before inputting this data to the controller. The cause of these non-zero mean values is still being investigated.

The next step before implementing the MIMO controller was to implement and test a simple blade pitch controller for the tower's f-a damping in Region 2. Implementation and testing of this controller was straightforward and validated our idea that blade collective pitch is an effective actuator for actively damping the tower's f-a motion in Region 2. After this last step, we were ready to implement the MIMO controller.

\section{Comparisons of MIMO State-Space Controller to Baseline Results}

We collected data on the CART while the Region 2 MIMO state-space controller was being tested. We then compared the test results to cases from the baseline control in Region 2 for similar dataset statistics. Because these controllers were tested at different times, a direct results comparison is difficult. Our objective was to show trends such as load mitigation. We examined datasets and extracted sections of data in which turbine operating parameters (such as wind speed and direction and yaw error) were similar for the baseline and state-space control cases. The results of our comparison are preliminary, and we need many more hours of operation for valid statistical comparisons between the controllers.

Table 2 shows the statistics of datasets in three cases. In each case there is a dataset for: 1) the baseline controller without the tower avoidance scheme, 2) the baseline controller with the tower avoidance scheme (shown in Figure 2), and 3) the state-space MIMO controller. The different cases were intended to reflect a variety of mean rotor speeds and wind speeds, although in retrospect there was not a large change in these values from one case to the next. Listed in this table are the mean and standard deviation (std) of the wind speed (at a height of $36.6 \mathrm{~m}$ ) and rotor speed (LSS rpm). In each case we tried to select datasets with similar statistics.

Table 2. Wind and Rotor-Speed Statistics for the Three Data-sets

\begin{tabular}{|c|c|c|c|c|}
\hline Dataset & \multicolumn{2}{|l|}{ Wind speed (m/s) } & \multicolumn{2}{l|}{ Rotor speed (rpm) } \\
\hline Case 1 (300 seconds) & mean & std & mean & std \\
\hline Baseline (no tower avoidance) & 8.46 & 1.62 & 28.9 & 4.39 \\
\hline Baseline (with tower avoidance) & 8.28 & 0.93 & 28.6 & 2.99 \\
\hline State-space & 8.23 & 1.61 & 29.2 & 6.15 \\
\hline & & & & \\
\hline Case 2 (500 seconds) & mean & std & mean & std \\
\hline Baseline (no tower avoidance) & 8.19 & 1.33 & 27.3 & 3.53 \\
\hline Baseline (with tower avoidance) & 7.31 & 1.20 & 26.0 & 4.15 \\
\hline State-space & 7.45 & 1.12 & 26.8 & 3.81 \\
\hline & & & & \\
\hline Case 3 (300 seconds) & mean & std & mean & std \\
\hline Baseline (no tower avoidance) & 9.42 & 1.19 & 30.1 & 3.48 \\
\hline Baseline (with tower avoidance) & 9.29 & 1.27 & 32.3 & 3.46 \\
\hline State-space & 8.78 & 1.28 & 31.4 & 4.50 \\
\hline
\end{tabular}


For each case we calculated the fatigue damage equivalent load (DEL) for the tower's s-s and f-a bending moments, and the blade flapwise and edgewise bending moments. ${ }^{16}$ Figures 15,16 and 17 show plots of normalized DELs for these three cases, with the results normalized to the baseline (no tower avoidance) dataset for each case.

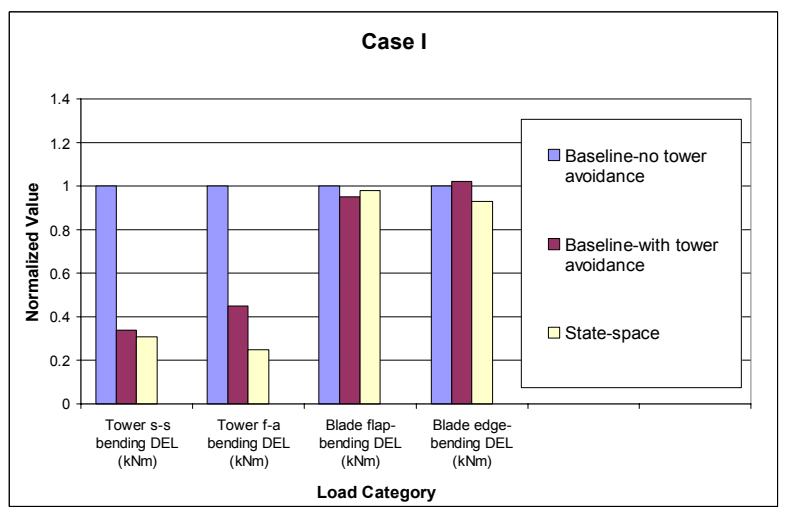

Figure 15. Measured CART data for Case 1.

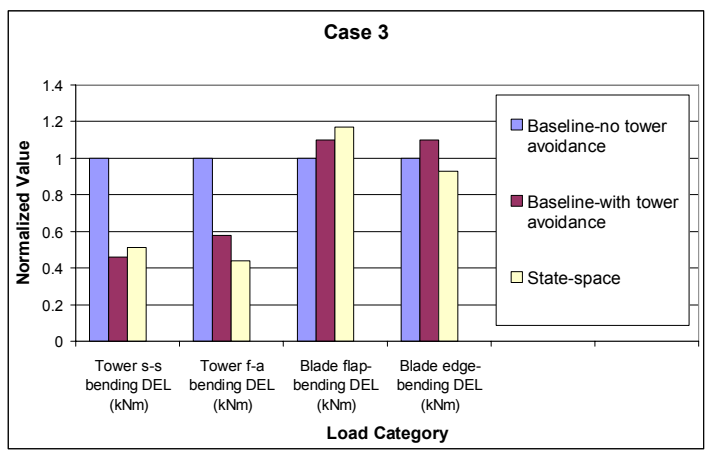

Figure 17. Measured CART data for Case 3.

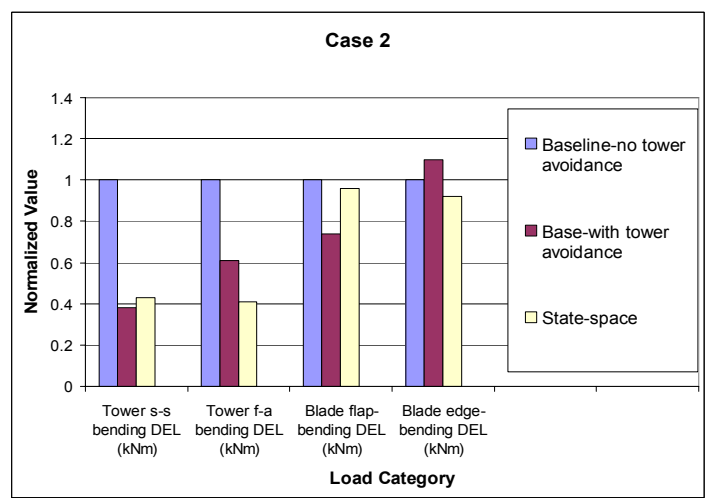

Figure 16. Measured CART data for Case 2.

Looking at each case, a large reduction in fatigue DEL for the tower's s-s and f-a bending moments is evident for the baseline with tower avoidance and state-space controllers compared to the baseline without tower avoidance. The baseline with the tower avoidance scheme seems to be about as effective as the state-space controller for mitigating the tower's s-s bending moment. The results for all three cases seem to indicate that the state-space controller mitigates the tower's f-a bending moment more effectively than the baseline with tower avoidance. We should note that the tower avoidance scheme could be included in the state-space controller but was not included for these studies.

Another important point is to see if the state-space controller results in higher fatigue DELs for other loads throughout the system compared to the baseline controllers. The blade flapwise- and edgewise-bending-moment DELs indicate there is no significant increase in DELs for the state-space controller compared to the baseline controllers (although for Case 3 the flapwise DEL for the state-space controller is slightly higher than the flapwise DEL for the baseline without tower avoidance). In future studies we will investigate the impact of this state-space controller on the fatigue DELs for the drive-train and gearbox.

We also calculated the maximum pitch rates for each case for the state-space controller (the pitch rates for the baseline controller with and without tower avoidance were zero, since pitch is held constant in Region 2). We also calculated the root mean square (RMS) of the pitch current to further compare actuator usage. Table 3 shows these values. The pitch servos must not exceed a pitch rate of 18 degrees per second (deg/s) or a current of $35 \mathrm{Amps}$ RMS. As we see from Table 3, the pitch servos were operating well below these limits. 
Table 3. Maximum Pitch Rates for the State-Space Controller

\begin{tabular}{|c|c|c|}
\hline Dataset & Pitch Rate (deg/s) & RMS Pitch Current (Amps) \\
\hline Case 1 & $\mathbf{5 . 6 4}$ & $\mathbf{1 2 . 6 9}$ \\
\hline Case 2 & $\mathbf{6 . 6 4}$ & $\mathbf{1 2 . 1 9}$ \\
\hline Case 3 & $\mathbf{6 . 8 9}$ & $\mathbf{1 5 . 7 3}$ \\
\hline
\end{tabular}

\section{Conclusions}

In this paper, we have shown the design, implementation, and testing of a MIMO controller to actively damp tower s-s and f-a motion by using generator torque and blade pitch in Region 2. Generator torque effectively damps tower s-s motion; blade pitch effectively damps tower f-a motion. When combined together in a MIMO controller, they actively damp both motions simultaneously without destabilizing the turbine.

We described the steps taken to implement this MIMO controller. We resolved issues of accelerometer response at high vibration frequencies. We included filter states in the control model so the controller could compensate for the phase lag produced when the tower-top accelerometer data is filtered before using it as an input to the controller. Another issue was the excitation of unmodeled dynamics at $38.5 \mathrm{rpm}$ rotor speed. We resolved this problem by designing a second controller with reduced tower damping gains and scheduling this controller to operate between 38 and $39 \mathrm{rpm}$. In future work we will design a filter to correctly attenuate accelerometer response at this frequency without affecting response at the tower first s-s and f-a natural frequencies.

Results from the MIMO controller showed large reductions in tower s-s and f-a bending moments compared to the baseline controller without the tower avoidance scheme. The MIMO controller produced similar tower s-s load alleviation but greater tower f-a load alleviation compared to the baseline controller with tower avoidance. The results of this study indicate that the MIMO controller did not increase the blade flapwise and edgewise loads relative to the baseline controller.

Another issue that arises in this study is the effect of the tower avoidance strategy (for the baseline controller) on Region 2 energy capture. This strategy causes the turbine to operate at a tsr that does not correspond to optimum Cp, with a corresponding decrease in energy capture. Further tests are required to ascertain whether the state-space controller (which does not have the tower avoidance strategy) results in greater Region 2 energy capture than the baseline controller with tower avoidance. If it does, the state-space controller would hold the advantage, because it alleviates tower loads at about the same level as the baseline with tower avoidance, but results in greater energy capture.

\section{Future Work}

Directions for future work include further field testing of the controls already implemented in the CART. We need many more hours of test data to show statistically that loads are reduced compared to baseline control results. We will investigate the impact of this state-space controller on the fatigue DELs for the drive-train and gearbox. Developing the proper filter to mitigate tower-top accelerometer response in the frequency range corresponding to unmodeled dynamics is important. This filtering must be done without affecting information needed by the controller at the tower first s-s and f-a natural frequencies. Implementation and testing of independent pitch control to mitigate spatially varying wind disturbances across the rotor disk will be designed and tested. Controls will also be designed and implemented on a three-bladed version of the CART. 


\section{References}

${ }^{1}$ Bossanyi, E. A., "Developments in Closed Loop Controller Design for Wind Turbines," $19^{\text {th }}$ ASME Wind Energy Conference, Reno, NV, 2000, pp. 64-74.

${ }^{2}$ Burton, T., Sharpe, D., Jenkins, N., and Bossanyi, E., 2001, Wind Energy Handbook, John Wiley \& Sons, LTD, New York, pp. 488-489.

${ }^{3}$ Wright, A. D., and Balas, M., "Design of State-Space-Based Control Algorithms for Wind Turbine Speed Regulation," ASME J. Solar Energy Engineering, Vol. 125, No. 4, November 2003, pp. 386-395.

${ }^{4}$ Wright, A. D., and Balas, M., "Design of Controls to Attenuate Loads in the Controls Advanced Research Turbine," ASME J. Solar Energy Engineering, Vol. 126, No. 4, November 2004, pp. 1083-1091.

${ }^{5}$ Wright, A. D., "Control Design for Flexible Wind Turbines," Ph.D. Dissertation, Department of Aerospace Engineering Sciences, University of Colorado, Boulder, CO, 2003.

${ }^{6}$ Stol, K., and Balas, M., "Periodic Disturbance Accommodating Control for Blade Load Mitigation in Wind Turbines," ASME J. Solar Energy Engineering, Vol. 125, No. 4, November 2003, pp. 379-385.

${ }^{7}$ Stol, K., "Disturbance Tracking Control and Blade Load Mitigation for Variable-Speed Wind Turbines," ASME J. Solar Energy Engineering, Vol. 125, No. 4, November 2003, pp. 396-401.

${ }^{8}$ Stol, K., and Fingersh, L., "Wind Turbine Field Testing of State-Space Control Designs," National Renewable Energy Laboratory, NREL/SR-500-35061, Golden, CO, 2004.

${ }^{9}$ Wright, A., Stol, K., and Fingersh, L., "Progress in Implementing and Testing State-Space Controls for the Controls Advanced Research Turbine," 24th ASME Wind Energy Conference, Reno, NV, 2005, pp. 88-100.

${ }^{10}$ Stol, K., Zhao, W., and Wright, A., "Individual Blade Pitch Control for the Controls Advanced Research Turbine (CART)," ASME J. Solar Energy Engineering, Vol. 128, No. 4, November 2006, pp. 498-505.

${ }^{11}$ Wright, A., Fingersh, L., and Balas, M., "Testing State-Space Controls for the Controls Advanced Research Turbine," ASME J. Solar Energy Engineering, Vol. 128, No. 4, November 2006, pp. 506-515.

${ }^{12}$ Johnson, K. E., Fingersh, L., Balas, M., and Pao, L. Y., "Methods for Increasing Region 2 Power Capture on a Variable Speed HAWT,” ASME J. Solar Energy Engineering, Vol. 126, No. 4, November 2004, pp. 1092-1100.

${ }^{13}$ Fingersh, L., and Johnson, K., "Baseline Results and Future Plans for the NREL Controls Advanced Research Turbine," $23^{\text {rd }}$ ASME Wind Energy Conference, Reno, NV, 2004, pp. 87-93.

${ }^{14}$ Jonkman, J. M., and Buhl, M. L., "FAST User's Guide,” National Renewable Energy Laboratory, NREL/EL-500-38230, Golden, CO, 2005.

${ }^{15}$ Kwakernaak, H., and Sivan, R., Linear Optimal Control Systems, Wiley Interscience, NY, 1972, pp. $207-237$.

${ }^{16}$ Sutherland, H. J., "On the Fatigue Analysis of Wind Turbines," Sandia National Laboratories, SAND99-0089, Albuquerque, NM, 1999. 


\section{REPORT DOCUMENTATION PAGE}

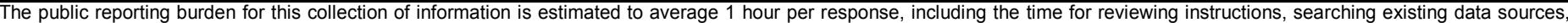

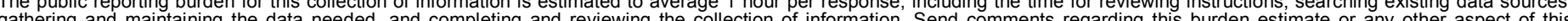

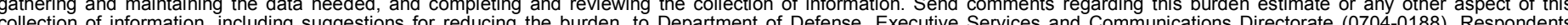

should be aware that notwithstanding any other provision of law, no

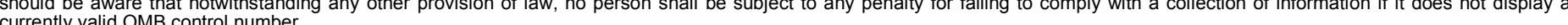

PLEASE DO NOT RETURN YOUR FORM TO THE ABOVE ORGANIZATION.

\begin{tabular}{l|l|l|l} 
1. REPORT DATE $(D D-M M-Y Y Y Y)$ & 2. & REPORT TYPE & 3. DATES COVERED (FrOm - TO)
\end{tabular}

January 2007

Conference paper

4. TITLE AND SUBTITLE

Designing and Testing Controls to Mitigate Tower Dynamic Loads in

the Controls Advanced Research Turbine

6. AUTHOR(S)

A.D. Wright, L.J. Fingersh, and K.A. Stol 5a. CONTRACT NUMBER

DE-AC36-99-GO10337

5b. GRANT NUMBER

5c. PROGRAM ELEMENT NUMBER

5d. PROJECT NUMBER

NREL/CP-500-40932

5e. TASK NUMBER

WER7.2701

5f. WORK UNIT NUMBER

7. PERFORMING ORGANIZATION NAME(S) AND ADDRESS(ES)

National Renewable Energy Laboratory

1617 Cole Blvd.

Golden, CO 80401-3393

9. SPONSORING/MONITORING AGENCY NAME(S) AND ADDRESS(ES)

10. SPONSOR/MONITOR'S ACRONYM(S)

NREL

11. SPONSORING/MONITORING AGENCY REPORT NUMBER

12. DISTRIBUTION AVAILABILITY STATEMENT

National Technical Information Service

U.S. Department of Commerce

5285 Port Royal Road

Springfield, VA 22161

13. SUPPLEMENTARY NOTES

14. ABSTRACT (Maximum 200 Words)

This report describes NREL's efforts to design, implement, and test advanced controls for maximizing energy

extraction and reducing structural dynamic loads in wind turbines.

15. SUBJECT TERMS

wind energy; wind turbines; control systems

\begin{tabular}{l}
\hline \multicolumn{3}{|l|}{ 16. SECURITY CLASSIFICATION OF: } \\
\hline \begin{tabular}{l|l|l|} 
a. REPORT & b. ABSTRACT & c. THIS PAGE \\
Unclassified & Unclassified & Unclassified \\
& & \\
\hline
\end{tabular} \\
\hline
\end{tabular}

\begin{tabular}{|c|c|}
\hline $\begin{array}{l}\text { 17. LIMITATION } \\
\text { OF ABSTRACT }\end{array}$ & $\begin{array}{l}\text { 18. NUMBER } \\
\text { OF PAGES }\end{array}$ \\
\hline UL & \\
\hline
\end{tabular}

19a. NAME OF RESPONSIBLE PERSON

19b. TELEPHONE NUMBER (Include area code) 